\title{
OPEN $\mathrm{Ni}_{2} \mathrm{P}$ nanocrystals embedded Ni-MOF nanosheets supported on nickel foam as bifunctional electrocatalyst for urea electrolysis
}

\author{
Haitao Wang ${ }^{1}$, Haiyan Zou ${ }^{1}$, Yingying Liu ${ }^{1}$, Zhenglong Liu ${ }^{1}$, Wenshuang Sun ${ }^{1}$, \\ Kunyi Andrew Lin ${ }^{2}$, Tielong Li ${ }^{1 \bowtie}$ \& Shuangjiang Luo ${ }^{3 凶}$
}

It's highly desired but challenging to synthesize self-supporting nanohybrid made of conductive nanoparticles with metal organic framework (MOF) materials for the application in the electrochemical field. In this work, we report the preparation of $\mathrm{Ni}_{2} \mathrm{P}$ embedded $\mathrm{Ni}$-MOF nanosheets supported on nickel foam through partial phosphidation ( $\left.\mathrm{Ni}_{2} \mathrm{P} @ \mathrm{Ni}-\mathrm{MOF} / \mathrm{NF}\right)$. The self-supporting $\mathrm{Ni}_{2}$ P@Ni-MOF/NF was directly tested as electrode for urea electrolysis. When served as anode for urea oxidation reaction (UOR), it only demands $1.41 \mathrm{~V}$ (Vs RHE) to deliver a current of $100 \mathrm{~mA} \mathrm{~cm}^{-2}$. And the overpotential of $\mathrm{Ni}_{2} \mathrm{P} @ \mathrm{Ni}-\mathrm{MOF} / \mathrm{NF}$ to reach $10 \mathrm{~mA} \mathrm{~cm}^{-2}$ for hydrogen evolution reaction HER was only $66 \mathrm{mV}$, remarkably lower than $\mathrm{Ni}_{2} \mathrm{P} / \mathrm{NF}(133 \mathrm{mV}$ ). The exceptional electrochemical performance was attributed to the unique structure of $\mathrm{Ni}_{2} \mathrm{P} @ \mathrm{Ni}-\mathrm{MOF}$ and the well exposed surface of $\mathrm{Ni}_{2} \mathrm{P}$. Furthermore, the $\mathrm{Ni}_{2} \mathrm{P} @ \mathrm{Ni}-\mathrm{MOF} / \mathrm{NF}$ demonstrated outstanding longevity for both HER and UOR. The electrolyzer constructed with $\mathrm{Ni}_{2} \mathrm{P} @ \mathrm{Ni}-\mathrm{MOF} / \mathrm{NF}$ as bifunctional electrode can attain a current density of $100 \mathrm{~mA} \mathrm{~cm}^{-2}$ at a cell voltage as low as $1.65 \mathrm{~V}$. Our work provides new insights for prepare MOF based nanohydrid for electrochemical application.

In recent years, the application of metal organic frameworks (MOFs) in the electrochemical field, especially electrocatalysis, has attracted considerable interest. The major appeals of the electrochemical application of MOFs are their large surface area, well-defined pores and tunable chemical composition ${ }^{1,2}$. However, the direct use of MOFs as electrode is often limited due to the poor intrinsic conductivity. So, MOFs are more often used as precursors to prepare advanced electrocatalysts through carbonization at high temperature ${ }^{3}$. The organic ligands in the MOFs are pyrolyzed to form graphitized/amorphous carbon matrix that could serve as freeway for electron flow. As a result, the MOFs-derived material through carbonization exhibited enhanced electrochemical activity for both hydrogen evolution reaction (HER) and oxygen evolution reaction (OER) due to the dramatically increased conductivity ${ }^{4}$. The electrocatalytic performance of the carbonized material can be further boosted by phosphidation ${ }^{5}$. However, the fascinating pore structure of MOFs is largely destroyed during the heat treatment, vanishing the advantages associated with the well-defined pore structure as well as high specific surface area ${ }^{6}$.

In recent years, MOF based nanohybrids prepared by integration of nanoparticles with MOF have attracted considerable attention ${ }^{7,8}$. Beside utilizing the super adsorption capability of MOF, such integration strategy could tuning the microenvironment of the nanoparticles to improve their catalytic activity ${ }^{8}$. Nevertheless, it is still very challenging to synthesize self-supporting MOF-nanoparticles nanohybrids, which is highly desired for the application in the electrochemical field.

On the other hand, OER is a thermodynamically sluggish multi-electron process with large over-potential, leading to energy consumption surge for electrochemical hydrogen production ${ }^{9}$. Moreover, it is a formidable challenge to completely avoid the formation of explosive $\mathrm{H}_{2} / \mathrm{O}_{2}$ mixtures during water electrolysis ${ }^{10}$. Replacing OER with alternative electrochemical oxidation reaction offers an effective way to address these drawbacks ${ }^{11}$. So far, urea, methanol and hydrazine electrochemical oxidation have been explored as alternative anode reaction ${ }^{12-16}$.

\footnotetext{
${ }^{1}$ Tianjin Key Laboratory of Environmental Technology for Complex Trans-Media Pollution, MOE Key Laboratory of Pollution Processes and Environmental Criteria, College of Environmental Science and Engineering, Nankai University, Tianjin 300350, China. ${ }^{2}$ Department of Environmental Engineering \& Innovation and Development Center of Sustainable Agriculture \& Research Center of Sustainable Energy and Nanotechnology, National Chung Hsing University, 250 Kuo-Kuang Road, Taichung, Taiwan. ${ }^{3}$ Institute of Process Engineering, Chinese Academy of Sciences, Beijing 100190, China.『email: litielong@nankai.edu.cn; sjluo@ipe.ac.cn
} 

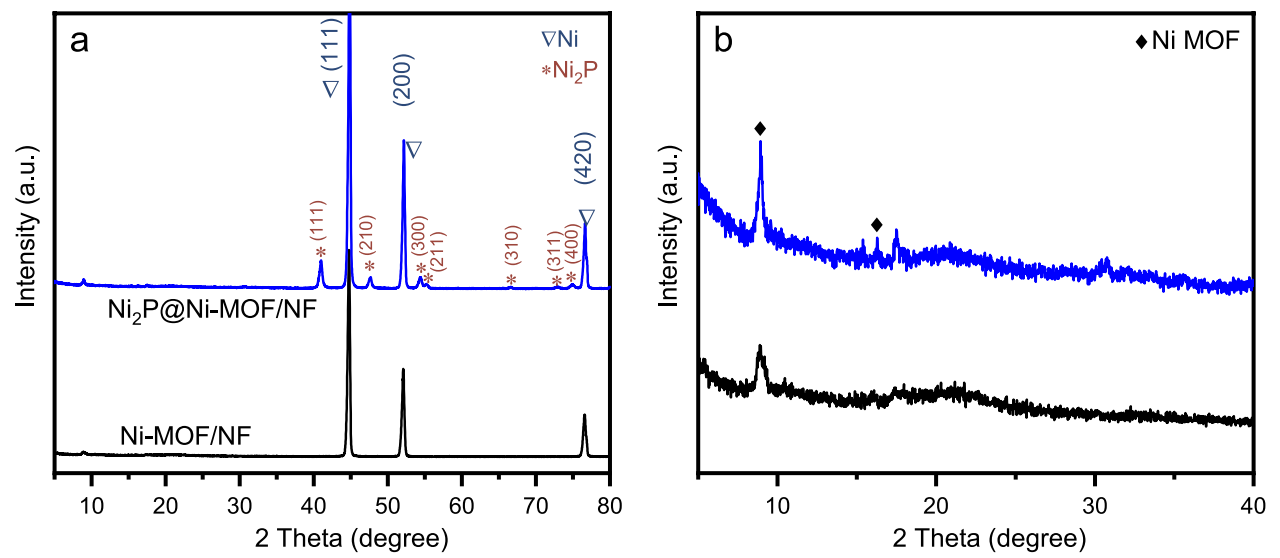

Figure 1. (a) Powder XRD pattern of Ni-MOF/NF and $\mathrm{Ni}_{2} \mathrm{P} @ \mathrm{Ni}-\mathrm{MOF} / \mathrm{NF}$ and $(\mathbf{b})$ enlarged XRD pattern on an expanded $y$-axis scale.

Compared with others, electrochemical oxidation of urea (UOR) has multiple advantages: (1) urea is a widely available commodity with merits such as non-toxic, high soluble in water, non-flammable, high energy density, easy storage and transportation; (2) the end products of UOR are harmless gases $\mathrm{CO}_{2}$ and $\mathrm{N}_{2}$; (3) Furthermore, it is feasible to extract energy from urea-rich wastewater such as human/animal urine, effluents discharged from urea synthesis factory ${ }^{17-19}$. Since the application of earth-abundant nickel as electrocatalyst for UOR was first reported by $\mathrm{G}$. Botte et $\mathrm{al}^{20}$, various nickel-containing nickel materials such as nickel oxides, sulfides, phosphides and alloys have been extensively explored as electrocatalyst for $\mathrm{UOR}^{21-35}$.

Herein, we report a feasible way to prepare $\mathrm{Ni}_{2} \mathrm{P}$ nanocrystals embedded $\mathrm{Ni}(\mathrm{BDC})(\mathrm{DMF}) \mathrm{MOF}$ supported on nickel foam $\left(\mathrm{Ni}_{2} \mathrm{P} @ \mathrm{Ni}-\mathrm{MOF} / \mathrm{NF}\right)$ through a direct phosphidation process. During the phoshidation process, part of the nickel atoms in the Ni-MOF transformed into $\mathrm{Ni}_{2} \mathrm{P}$ nanoparticles. The self-supporting $\mathrm{Ni}_{2} \mathrm{P} @ \mathrm{Ni}-\mathrm{MOF} /$ NF was directly used as electrode for HER and UOR without the use of any polymer binders. The overpotential was only $66 \mathrm{mV}$ to drive HER at a current density of $10 \mathrm{~mA} \mathrm{~cm}^{-2}$. To drive UOR at a current density of $100 \mathrm{~mA}$ $\mathrm{cm}^{-2}$, it only needs a potential as low as $1.41 \mathrm{~V}$ (vs RHE). The superior HER and UOR performance of the $\mathrm{Ni}_{2} \mathrm{P} @$ $\mathrm{Ni}-\mathrm{MOF} / \mathrm{NF}$ was attributed to the enhanced conductivity, fast release of the gases bubbles from the surfaces of the electrode as well as the tuning of the microenvironment of $\mathrm{Ni}_{2} \mathrm{P}$ nanoparticls by $\mathrm{Ni}-\mathrm{MOF}$. The electrolyzer constructed with $\mathrm{Ni}_{2} \mathrm{P} @ \mathrm{Ni}-\mathrm{MOF} / \mathrm{NF}$ as both bifunctional electrode could deliver a current density of $100 \mathrm{~mA}$ $\mathrm{cm}^{-2}$ in $1 \mathrm{M} \mathrm{NaOH}$ with the presence of $0.33 \mathrm{M}$ urea at $1.65 \mathrm{~V}$, which was $0.26 \mathrm{~V}$ lower than water electrolysis.

\section{Results and discussion}

Materials characterization. To synthesize the $\mathrm{Ni}_{2} \mathrm{P} @ \mathrm{Ni}-\mathrm{MOF} / \mathrm{NF}$ electrode, the $\mathrm{Ni}(\mathrm{BDC})(\mathrm{DMF}) \mathrm{MOF}$ was first grown on NF by a solvothermal method at $140^{\circ} \mathrm{C}$ and the sample was labelled as Ni-MOF/NF. Afterwards, the Ni-MOF was converted to $\mathrm{Ni}_{2} \mathrm{P} @ \mathrm{Ni}-\mathrm{MOF}$ by a direct phosphidation process carried out at $300{ }^{\circ} \mathrm{C}$. Powder X-ray diffraction (XRD) was first employed to get the composition and phase of the Ni-MOF/NF. Two sharp diffraction peaks at $44.9^{\circ}$ and $52.2^{\circ}$ were observed in the XRD pattern of Ni-MOF/NF (Fig. 1a), corresponding to the (111) and (200) planes of face-centered cubic nickel (JCPDS No. 01-1260). Apparently, the diffraction peaks of Ni-MOF were relatively weak. Enlarged XRD patterns on an expanded y-axis scale was provided in Fig. $1 \mathrm{~b}$ for clarity. The diffraction peak at $8.9^{\circ}$ and $17.5^{\circ}$ was assigned to Ni-MOF (CCDC No. 638866). After phosphidation process, four new peaks emerged at $40.9^{\circ}, 47.6^{\circ}, 54.4^{\circ}$ and $55.1^{\circ}$, which were attributed to the (111), (210), (300) and (211) planes of hexagonal $\mathrm{Ni}_{2} \mathrm{P}$ (JCPDS No.03-0953). The diffraction peaks at 8.9 and $17.5^{\circ}$ associated with Ni-MOF did not disappear, indicating only part of the Ni-MOF has been converted to $\mathrm{Ni}_{2} \mathrm{P}$. The thermogravimetric analysis curve shown in Fig. $\mathrm{S} 1$ confirmed that $300{ }^{\circ} \mathrm{C}$ was not high enough to cause the decomposition of Ni-MOF.

The FTIR spectra of the nanosheets before and after phosphidation are shown in Fig. S2. Overall, the absorption bands of nanosheets became weaker after phosphidation. Nevertheless, the FTIR result verified the partial preserve of Ni-MOF. The absorption band around $3444 \mathrm{~cm}^{-1}$ was assigned to the stretching vibration of $\mathrm{NH}$. The asymmetric and symmetric stretching modes of $\mathrm{C}=\mathrm{O}$ appeared at 1582 and $1369 \mathrm{~cm}^{-1}$, respectively $\mathrm{y}^{36,37}$. The band at 1087 was attributed to the stretching vibration of $\mathrm{C}-\mathrm{O}$ of carboxylic acid group. And narrow bands at 1025 and $748 \mathrm{~cm}^{-1}$ were attributed to $\delta(\mathrm{C}-\mathrm{H})$ and $\gamma(\mathrm{C}-\mathrm{H})$ vibration of aromatic rings, respectively.

As revealed by the SEM characterization (Fig. S3), the Ni foam exhibited a highly open pore structure with pore size around several hundred microns. The high resolution SEM image revealed that the nickel skeleton was composed of relatively smooth large compact Ni grains. After Ni-MOF growth, the surfaces of Ni foam were uniformly covered with 2D nanosheets (Fig. 2). The Ni-MOF nanosheets exhibited a leaf-like morphology with lateral size 4-7 microns, which interlaced with each other to form a nest-like structure. The high resolution SEM image shown in Fig. 2c disclosed the fine vein-like structure on the surfaces of the as-grown Ni-MOF. After phosphidation process, the skeleton of $\mathrm{Ni}$ foam was still uniformly covered with nanosheets (Fig. 2d). But compared to Ni-MOF/NF sample, the population of the nanosheets was apparently decreased. As it can be clearly seen in the high resolution SEM images (Fig. 2e, f), the fine vein-like structures disappeared after phosphidation and the 

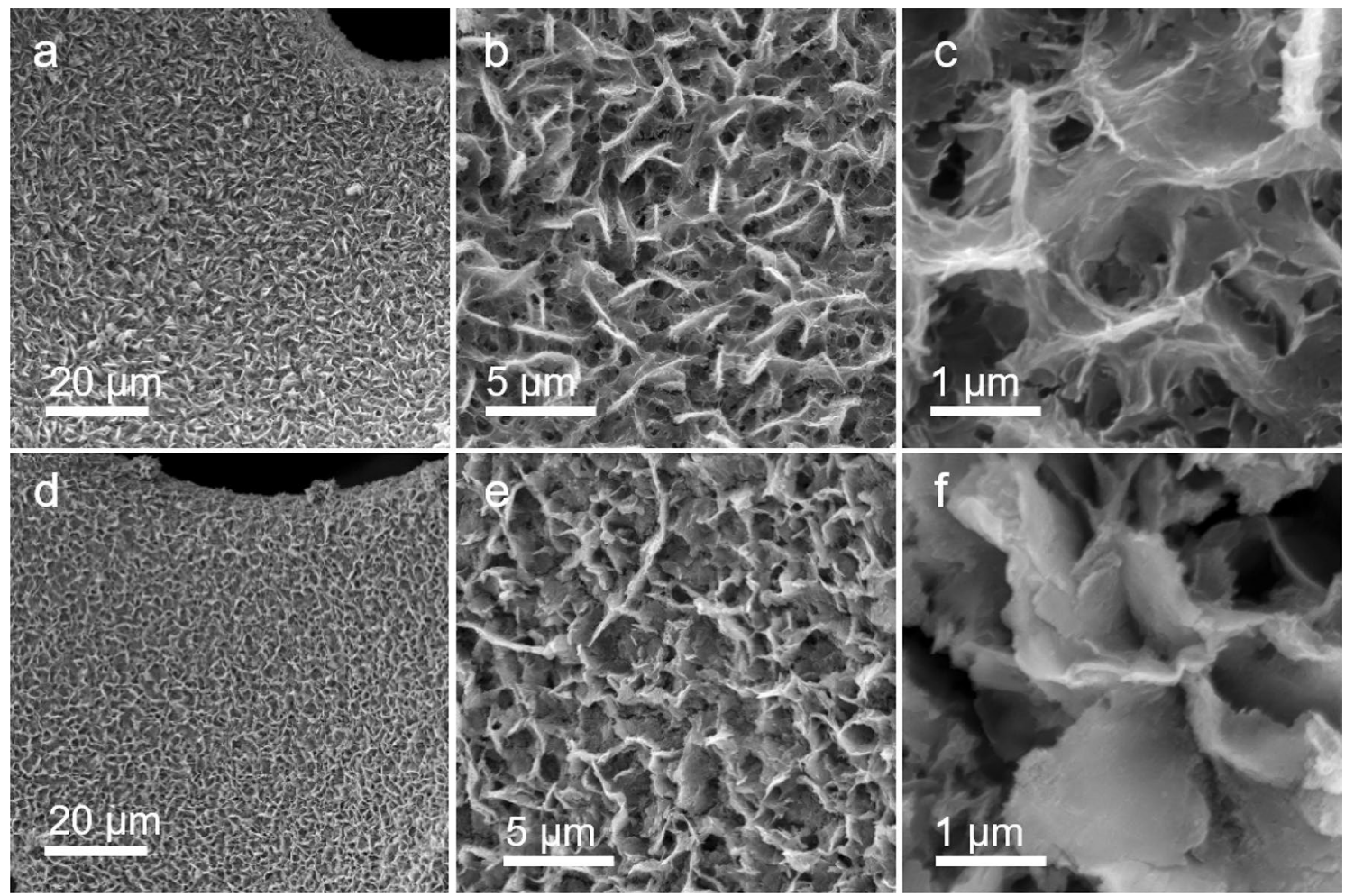

Figure 2. SEM image of $\mathrm{Ni}-\mathrm{MOF} / \mathrm{NF}(\mathbf{a}-\mathbf{c})$ and $\mathrm{Ni}_{2} \mathrm{P} @ \mathrm{Ni}-\mathrm{MOF} / \mathrm{NF}(\mathbf{d}, \mathbf{e})$ under different scales.

surfaces of the 2D nanosheets became smoother. Nevertheless, the sample still exhibited nest-like morphology composed of 2D nanosheets. The successfully incorporation of $\mathrm{P}$ elements through phosphidation was confirmed by the energy-dispersive X-ray (EDX) spectrum (Fig. S4).

For TEM characterization, the $\mathrm{Ni}_{2} \mathrm{P} @ \mathrm{Ni}-\mathrm{MOF}$ nanosheets were scraped off the nickel foam and dispersed in ethanol with the help of vortex shaking instead of sonication to minimize the damage. The TEM image shown in Fig. 3 a reveals the 2 dimensional nature of the $\mathrm{Ni}_{2} \mathrm{P} @ \mathrm{Ni}-\mathrm{MOF}$ sample. The selective area electron diffraction (SAED) pattern displayed rings with bright spots, indicating the polycrystalline nature of the sample (Fig. 3b). High resolution TEM (HR-TEM) image revealed that the surface of the nanosheet was decorated with nearly monodispersed nanoperticles with size around $8 \mathrm{~nm}$ (Fig. 3c). The formation of $\mathrm{Ni}_{2} \mathrm{P}$ nanoparticles was limited by the available nickel atoms in the MOF nanosheets, similar to the formation of metal or metal oxide nanoparticles in layer double hydroxide ${ }^{38}$. The HR-TEM image of a single nanoparticle shows distinct lattice fringes with interplanar d-spacing determined to be $0.22 \mathrm{~nm}$ (Fig. 3d), which was attributed to the (111) plane of $\mathrm{Ni}_{2} \mathrm{P}$. According to the elemental mapping image, the $\mathrm{Ni}, \mathrm{P}, \mathrm{C}$ and $\mathrm{N}$ elements were uniformly distributed in the $\mathrm{Ni}_{2} \mathrm{P} @$ $\mathrm{Ni}-\mathrm{MOF}$ nanosheet (Fig. 3e). The atomic ratio of Ni:P was $\sim 5.6: 1$, proving the partial transformation of the $\mathrm{Ni}$ atoms in the Ni-MOF to $\mathrm{Ni}_{2} \mathrm{P}$.

XPS was performed employed to investigate the surface chemical composition and electronic state of elements of the nanosheets before and after phosphidation. As shown in the XPS survey spectra (Fig. 4a), besides the $\mathrm{Ni}, \mathrm{C}$ and $\mathrm{N}$ elements, new signal peak positioned at $133 \mathrm{eV}$ corresponding to $\mathrm{P}$ element after phosphidation process. The high resolution Ni $2 p$ XPS spectrum of Ni-MOF displayed four prominent peaks (Fig. $4 \mathrm{~b}$ ), the two peaks positioned at 855.6 and $873.5 \mathrm{eV}$ are assigned to $\mathrm{Ni} 2 \mathrm{p}_{3 / 2}$ and $\mathrm{Ni} 2 \mathrm{p}_{1 / 2}$, respectively ${ }^{39,40}$. The other two peaks positioned at 861.8 and $878.2 \mathrm{eV}$ are the corresponding satellite peaks of $\mathrm{Ni}_{2} \mathrm{p}_{3 / 2}$ and $\mathrm{Ni} 2 \mathrm{p}_{1 / 2}$, respectively. After phosphidation, two new peaks corresponding to reduced $\mathrm{Ni}^{\delta+}$ emerged at 852.8 and $870.0 \mathrm{eV}^{41}$. Meantime, both the $\mathrm{Ni} 2 \mathrm{p}_{3 / 2}$ and $\mathrm{Ni} 2 \mathrm{p}_{1 / 2}$ peaks shifted to higher binding energy, suggesting the charge transfer from nickel to phosphorus atoms. The high resolution C1s XPS spectrum of Ni-MOF nanosheets displays two main peaks and the one positioned at $288.3 \mathrm{eV}$ is assigned to $\mathrm{C}=\mathrm{O}$ (Fig. $4 \mathrm{c})^{42}$. The other peak positioned at $284.5 \mathrm{eV}$ could be deconvoluted into two peaks corresponding to C-C $(284.5 \mathrm{eV})$ and $\mathrm{C}-\mathrm{N}(285.0 \mathrm{eV})$, respectively. After phosphidation, the peak related to $\mathrm{C}-\mathrm{N}$ shifted $0.4 \mathrm{eV}$ to higher binding energy, suggesting the charge transfer from carbon to neighboring atoms. The N 1s XPS spectrum of Ni-MOF nanosheets only displays one peak at $399.9 \mathrm{eV}$ assigned to $\mathrm{C}-\mathrm{N}-\mathrm{C}$ from DMF (Fig. 4d). After phosphidation, the peak shifted slightly to lower binding energy to $399.6 \mathrm{eV}$, demonstrating the charge transfer from neighboring atoms to $\mathrm{N}$. The $\mathrm{N} 1 \mathrm{~s}$ peak could not be deconvoluted, suggesting that no graphitized nitrogen formed after phosphidation process. That was reasonable since the temperature of phosphidation process was too low to induce graphitization. The high resolution P 2p XPS spectrum exhibits two main characteristic peaks positioned at 129.3 and $134.7 \mathrm{eV}$ (Fig. 4e), which are assigned to P-Ni and oxidized phosphate species ${ }^{43,44}$. 


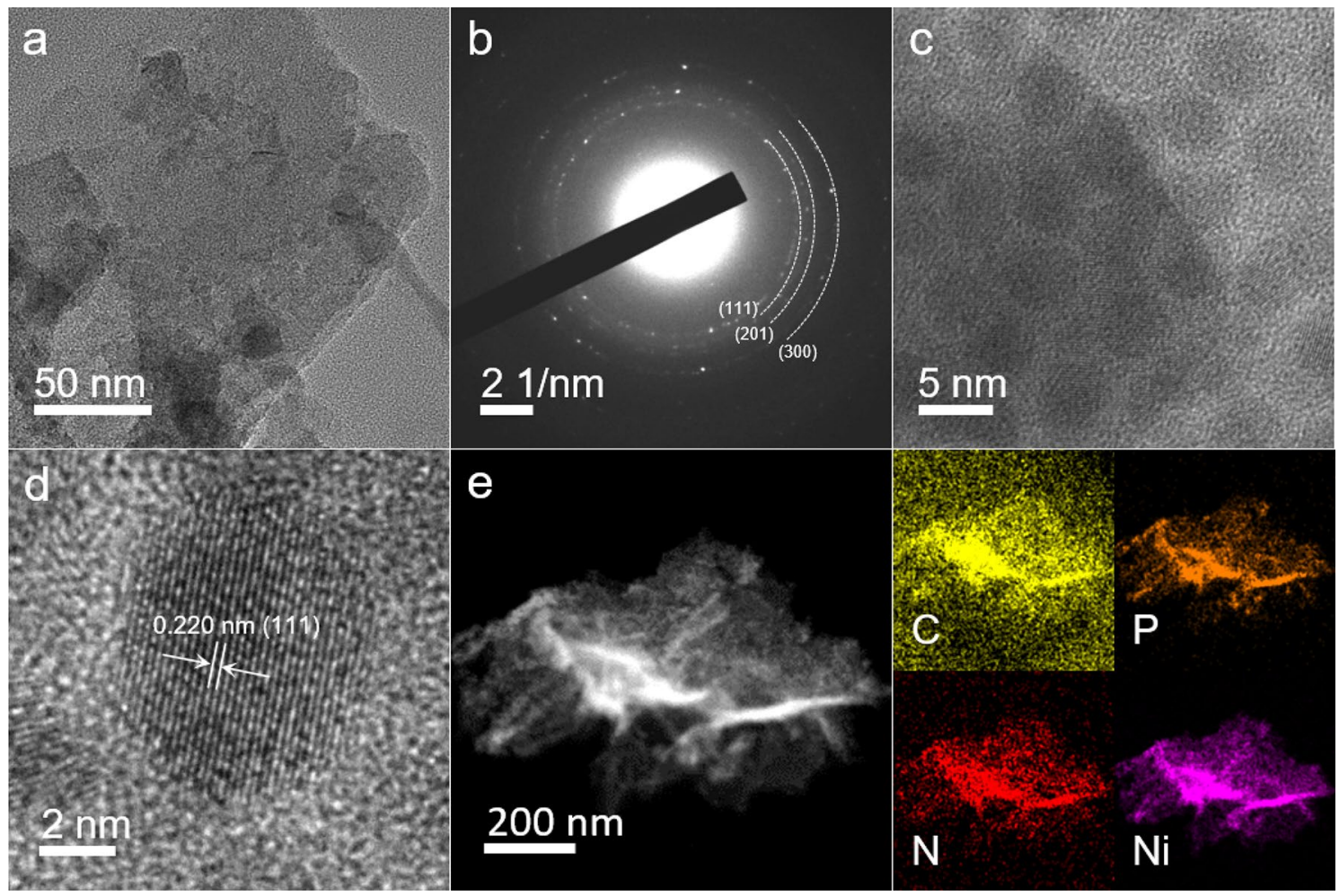

Figure 3. (a) TEM image, (b) SAED, (c, d) HRTEM image, and (e) elemental mapping image of $\mathrm{Ni}_{2} \mathrm{P} @$ Ni-MOF.
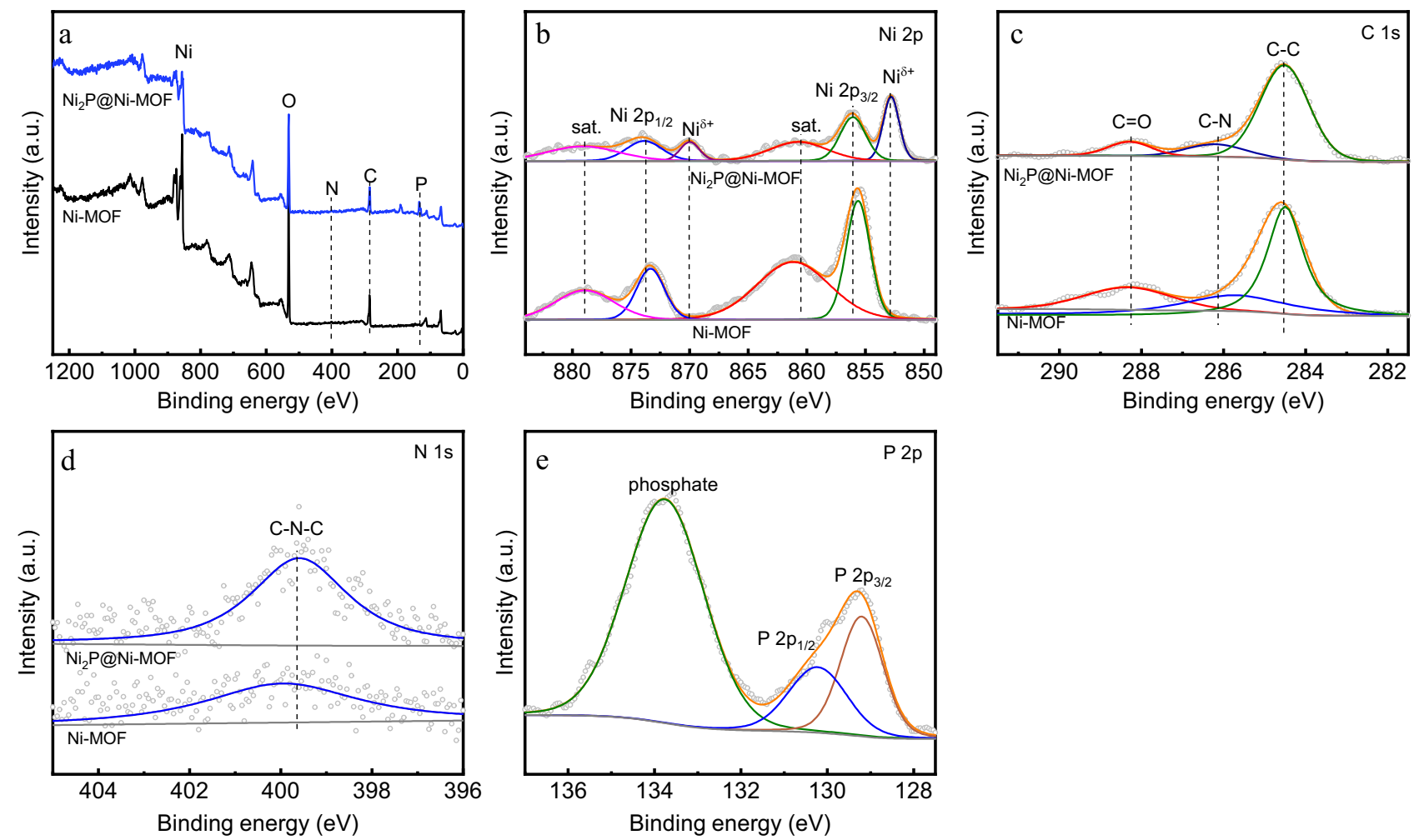

Figure 4. (a) XPS survey spectra of Ni-MOF/NF and $\mathrm{Ni}_{2} \mathrm{P} @ \mathrm{Ni}-\mathrm{MOF} / \mathrm{NF}$ and high resolution XPS spectra of (b) Ni 2p, (c) C 1 s, (d) N 1 s and (e) P 2p. All of the spectra were calibrated by C1s peak located at $284.8 \mathrm{eV}$. 

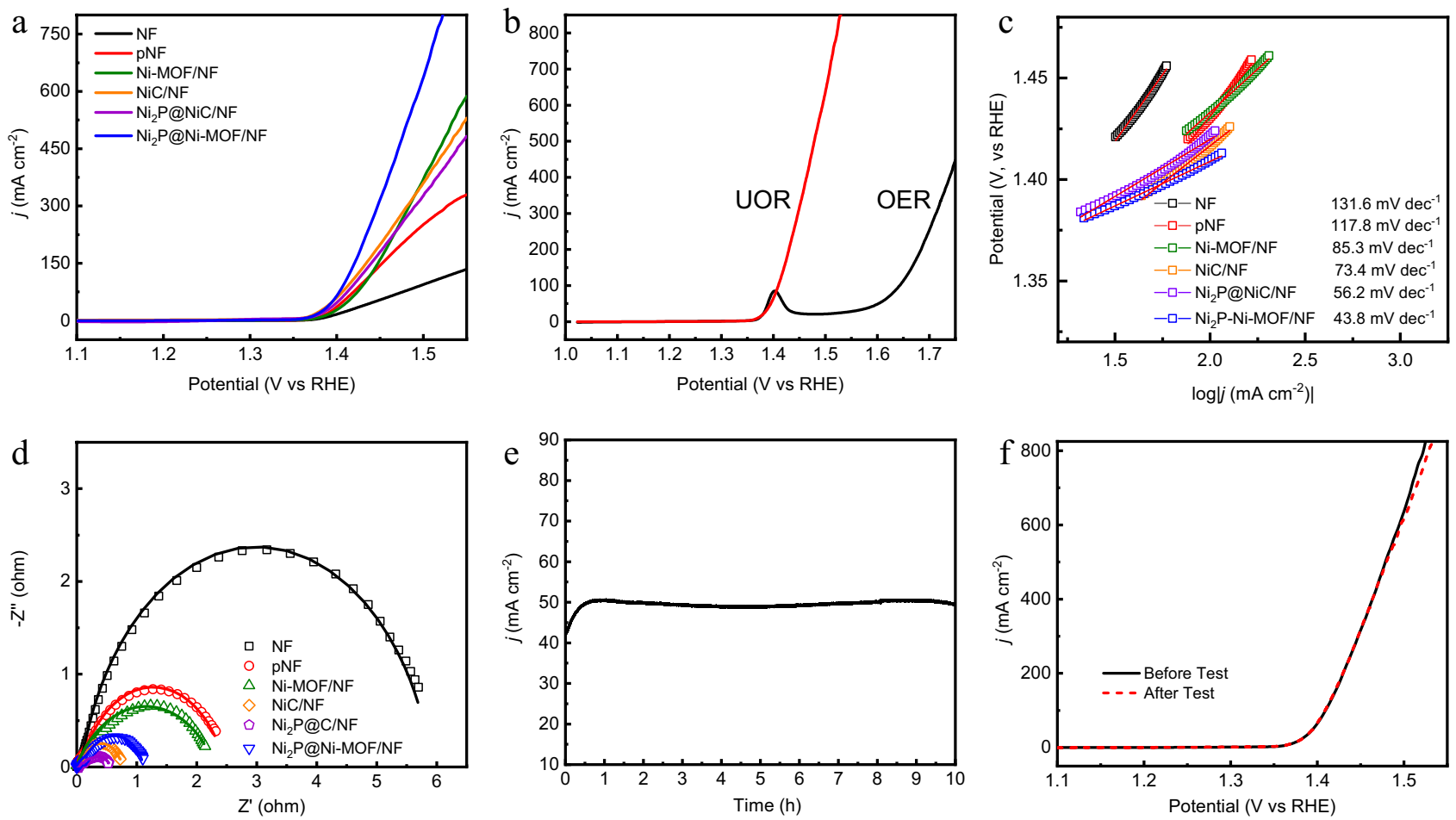

Figure 5. (a) LSV curves of $\mathrm{Ni}_{2} \mathrm{P} @ \mathrm{Ni}-\mathrm{MOF} / \mathrm{NF}, \mathrm{Ni}_{2} \mathrm{P} @ \mathrm{NiC} / \mathrm{NF}, \mathrm{NiC} / \mathrm{NF}, \mathrm{Ni}-\mathrm{MOF} / \mathrm{NF}, \mathrm{pNF}$ and $\mathrm{NF}$ in $1.0 \mathrm{M}$ $\mathrm{NaOH}$ with $0.33 \mathrm{M}$ urea. (b) LSV curve of $\mathrm{Ni}_{2} \mathrm{P} @ \mathrm{Ni}-\mathrm{MOF} / \mathrm{NF}$ in $1.0 \mathrm{M} \mathrm{NaOH}$ with or without $0.33 \mathrm{M}$ urea. (c) The corresponding Tafel plots and (d) the Nyquist plots of various electrodes. (e) Chronoamperometric (i-t) curve of $\mathrm{Ni}_{2} \mathrm{P} @ \mathrm{Ni}-\mathrm{MOF} / \mathrm{NF}$ for $10 \mathrm{~h}$. (f) LSV curves of $\mathrm{Ni}_{2} \mathrm{P} @ \mathrm{Ni}-\mathrm{MOF} / \mathrm{NF}$ before and after $10 \mathrm{~h}$ chronoamperometry test.

UOR performance. The UOR performance of various electrodes were evaluated by using LSV technique in a mixed solution containing $1 \mathrm{M} \mathrm{NaOH}$ and $0.33 \mathrm{M}$ urea. As shown in Fig. 5a, the initial oxidation potentials of UOR for various electrodes were almost the same, $1.36 \mathrm{~V}$ (vs RHE). This result suggested that the active species for UOR of various electrode were the same as reported in previous study ${ }^{45}$. The $\mathrm{Ni}_{2} \mathrm{P} @ \mathrm{Ni}-\mathrm{MOF} / \mathrm{NF}$ electrode demonstrated the best UOR activity, followed by Ni-MOF/NF. The potential to drive the UOR at $100 \mathrm{~mA} / \mathrm{cm}^{2}$ is only $1.41 \mathrm{~V}$, which is among the best when compared with the literature data (Table S1). The linear increase of the current density above $1.38 \mathrm{~V}$ (vs RHE) indicated the readily detachment of gases bubbles from the surfaces of the electrode ${ }^{45}$. The UOR performances of $\mathrm{NiC} / \mathrm{NF}$ and $\mathrm{Ni}_{2} \mathrm{P} @ \mathrm{NiC} / \mathrm{NF}$ were inferior to Ni-MOF/NF, which may be attributed to the encapsulation of nickel species by carbon.

The current density reported in this work was normalized to the projected area of the electrode, which could not reflect the intrinsic catalytic activity of the material ${ }^{46}$. However, it was impossible to accurately determine the loading amount of the active material on the electrode. So, we tried to normalize the current density to the electrochemically active surface area (ECSA), which was regarded to be directly correlated with the active sites for electrochemical reaction ${ }^{47}$. The ECSA of the electrode could be calculated by using the following equation,

$$
\mathrm{ECSA}=\mathrm{C}_{\mathrm{dl}} / \mathrm{C}_{\mathrm{s}}
$$

where $C_{d l}$ is the double-layer capacitance of the electrode, $C_{s}$ is the specific capacitance of the material. The $C_{\mathrm{dl}} s$ of various electrodes were determined from the $\mathrm{CV}$ curve obtained in a non-Faradic region (0.1-0.2 V) in $1 \mathrm{M}$ $\mathrm{NaOH}$ solution (Fig. S5 and Fig. S6a). Since $\mathrm{C}_{\mathrm{s}}$ s of various materials are unknown for, the ECSAs cannot be determined. The current density was therefore normalized to $\mathrm{C}_{\mathrm{dl}}$ by assuming that all materials have the same $\mathrm{C}_{\mathrm{s}}$ (Fig. S6b). Obviously, the Ni-MOF/NF electrode had the best performance, followed by $\mathrm{Ni}_{2} \mathrm{P} @ \mathrm{Ni}-\mathrm{MOF} / \mathrm{NF}$.

Since OER was the competitive reaction with UOR at higher potential, the OER performance was also investigated (Fig. 5b). An obvious anodic peak corresponding of the oxidation of $\mathrm{Ni}^{2+}$ to $\mathrm{Ni}^{3+}$ was observed in the polarization curve of OER at the potential of $1.40 \mathrm{~V}$ (vs RHE). By comparing the LSV curve of UOR to OER, it is clear that the oxidation of urea occurs upon the formation of $\mathrm{Ni}^{3+}$ species, demonstrating that UOR happens readily than OER. In sharp contrast to UOR, OER occurs at a relatively high potential (1.6 V vs RHE) after the completion of the oxidation of $\mathrm{Ni}^{2+}$ to $\mathrm{Ni}^{3+}$, revealing that the real catalyst for OER is $\mathrm{NiOOH}^{48}$. It is noteworthy that the current density for UOR reached $850 \mathrm{~mA} / \mathrm{cm}^{2}$ before the occurring of OER, which is the highest ever reported to the best of our knowledge. Tafel analyses were conducted to compare the UOR kinetics of various catalysts. As shown in Fig. $5 c$, the $\mathrm{Ni}_{2} \mathrm{P} @ \mathrm{Ni}-\mathrm{MOF} / \mathrm{NF}$ electrode exhibited the lowest Tafel slope of $43.8 \mathrm{mV} / \mathrm{dec}$, significantly smaller than other catalysts. The results indicated that the UOR with $\mathrm{Ni}_{2} \mathrm{P} @ \mathrm{Ni}-\mathrm{MOF} / \mathrm{NF}$ electrode occurred at faster kinetics than other electrodes. 

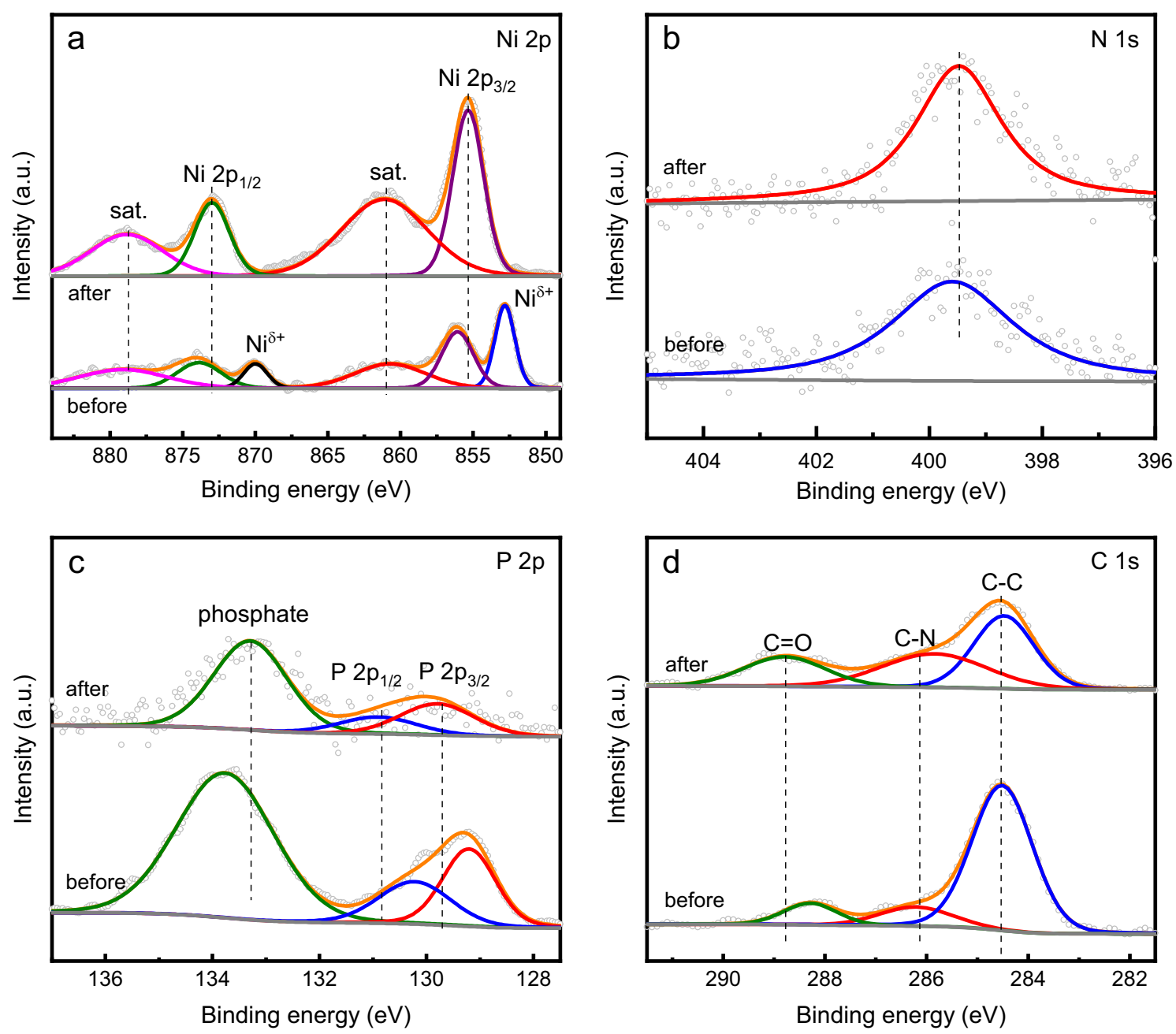

Figure 6. High resolution XPS spectra of (a) Ni 2p, (b) N 1 s, (c) P 2p and (d) C 1s in $\mathrm{Ni}_{2} \mathrm{P} @ \mathrm{Ni}-\mathrm{MOF} / \mathrm{NF}$ after durability test.

The charge transfer resistance is a critical influential parameter for electrochemical reaction, which is commonly negative correlated with conductivity of the electrode. In order to evaluate the charge transfer resistance during UOR, electrochemical impedance (EIS) tests were carried out at $1.42 \mathrm{~V}$. The best fitting was obtained using the equivalent circuit shown in Fig. S7. As shown in Fig. 5d, all of the Nyquist plots exhibited a semicircle shape. The smaller diameter of the semicircle, the lower the charge transfer resistance. Obviously, the $\mathrm{Ni}_{2} \mathrm{P} @ \mathrm{Ni}-\mathrm{MOF} /$ $\mathrm{NF}$ electrode is not the smallest, which is slight larger than that of $\mathrm{Ni}_{2} \mathrm{P} @ \mathrm{NiC} / \mathrm{NF}$ and $\mathrm{NiC} / \mathrm{NF}$. The fitting results indicated that the $\mathrm{Ni}_{2} \mathrm{P} @ \mathrm{NiC} / \mathrm{NF}$ had the smallest charge transfer resistance (Table $\mathrm{S} 2$ ), clearly demonstrating that high temperature carbonization and phosphidation was the best way to enhance the conductivity. On the other hand, the results also indicate that conductivity is not the only determinant factor for UOR.

Chronoamperometry test was conducted at $1.4 \mathrm{~V}$ (vs RHE) to investigate the durability of $\mathrm{Ni}_{2} \mathrm{P} @ \mathrm{Ni}-\mathrm{MOF} /$ NF electrode. As shown in Fig. 5e, the current density gradually increased from 42 to $50 \mathrm{~mA} \mathrm{~cm}^{-2}$ in the early stage, which may be attributed to the activation of electrode. At the end of the stability test, the current density declined by only $1.9 \%$, demonstrating the superior stability of the electrode. UOR involves gas evolution, the gas bubbles formed on the surface of the electrode need to be released promptly to avoid the blocking of the active $\operatorname{sites}^{49}$. The blocking effect will be exacerbated at constant applied potential, which leads drastic fluctuation of the current density ${ }^{50}$. It can be clearly seen from Fig. 5e that the current density fluctuation was negligible, suggesting the swiftly gases bubbles detachment from the electrode's surface. This fast detachment of gases bubbles was credited to the surface properties of the electrode and the porous structure of the nickel foam. The interconnected macroporous structure of nickel foam allows fast detachment of tiny gas bubbles, enabling it an ideal platform to prepare advanced electrodes for gas evolution reaction ${ }^{51,52}$. The LSV test was conducted again after durability test. As shown in Fig. 5f, the LSV curve overlapped with that collected before durability test. The results verified the excellent longevity of the electrode for UOR.

The $\mathrm{Ni}_{2} \mathrm{P} @ \mathrm{Ni}-\mathrm{MOF} / \mathrm{NF}$ electrode after stability test was first characterized by using XPS. As shown in Fig. 6a, the XPS peaks corresponding to the $\mathrm{Ni}^{\delta+}$ species decreased dramatically after test. And the XPS peaks related to $\mathrm{Ni} 2 \mathrm{p}$ shifted to higher binding energy level. The result indicated the oxidation of Ni species to higher valance state in the material. No change was observed for $\mathrm{N} 1$ s peak (Fig. 6b). The P 2p peak shifted to higher binding 

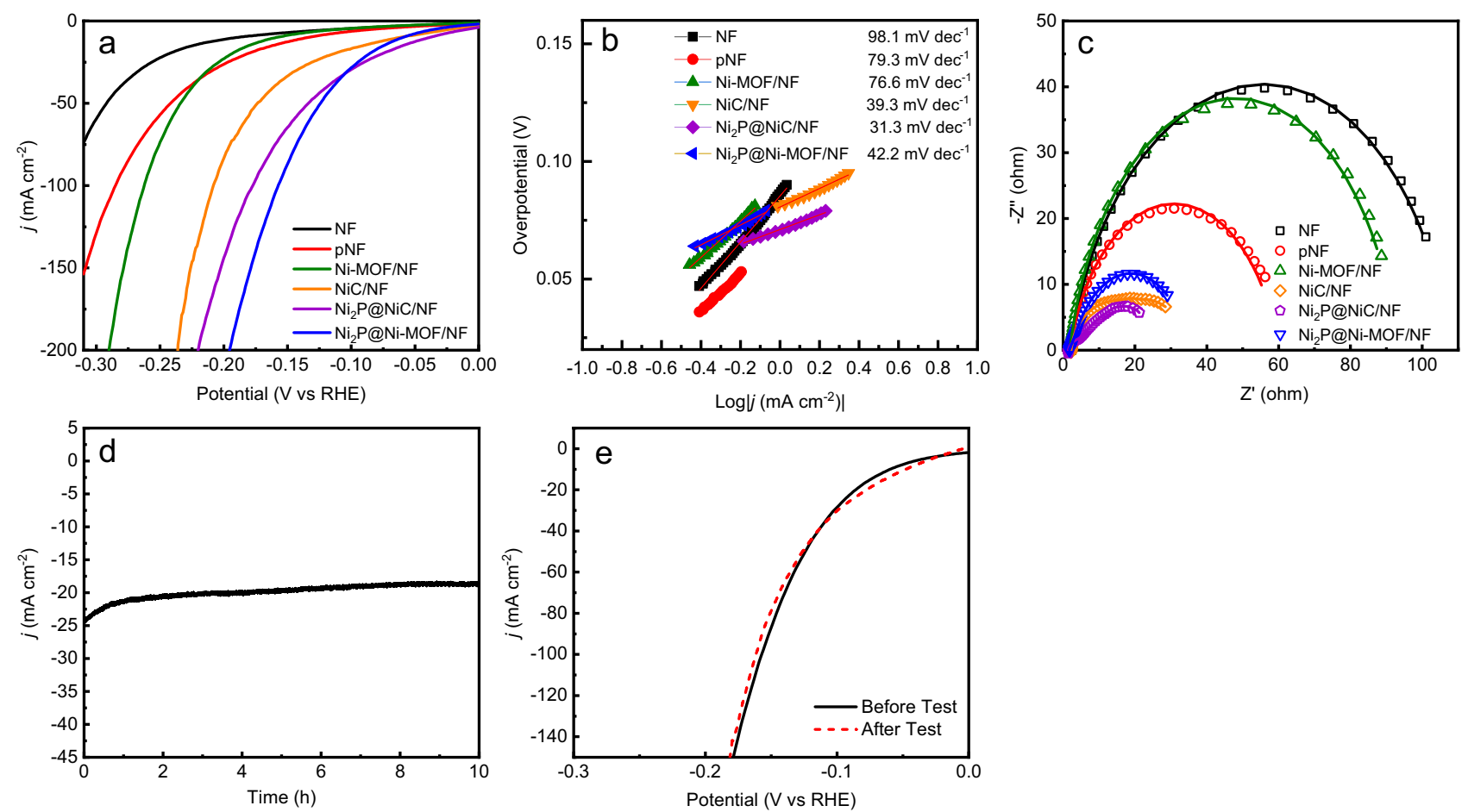

Figure 7. (a) LSV curves, (b) the corresponding Tafel plots and (c) the Nyquist plots of $\mathrm{Ni}_{2} \mathrm{P} @ \mathrm{Ni}-\mathrm{MOF} / \mathrm{NF}$, $\mathrm{Ni}_{2} \mathrm{P} @ \mathrm{NiC} / \mathrm{NF}, \mathrm{NiC} / \mathrm{NF}, \mathrm{Ni}-\mathrm{MOF} / \mathrm{NF}, \mathrm{pNF}$ and NF, (d) Chronoamperometric (i-t) curve of $\mathrm{Ni}_{2} \mathrm{P} @ \mathrm{Ni}-\mathrm{MOF} / \mathrm{NF}$ for $10 \mathrm{~h}$. (e) LSV curves of $\mathrm{Ni}_{2} \mathrm{P} @ \mathrm{Ni}-\mathrm{MOF} / \mathrm{NF}$ before and after durability test. The electrolyte was $1.0 \mathrm{M} \mathrm{NaOH}$ with $0.33 \mathrm{M}$ urea.

energy level, indicating the charge transfer form $\mathrm{P}$ atoms to neighboring atoms (Fig. $6 \mathrm{c}$ ). The shifting to high energy level was also observed for the XPS peak corresponding to $\mathrm{C}=\mathrm{O}$ (Fig. 6d). Overall, the XPS result indicated the occurrence of the oxidation of surface elements of the electrode. The morphology of the catalyst was further characterized by using SEM and TEM. As shown in Fig. S8a, no apparent morphology deterioration was found after test. And the lattice fringes of $\mathrm{Ni}_{2} \mathrm{P}$ could also be resolved as shown in the TEM image (Fig. S8b). The elemental mapping confirmed that the main components of the catalyst was still the same (Fig. S8c).

HER performance. Nickel phosphides such as $\mathrm{Ni}_{2} \mathrm{P}$ and $\mathrm{Ni}_{5} \mathrm{P}_{4}$ have been extensively explored as electrocatalyst for HER ${ }^{53,54}$. So, the HER performance of $\mathrm{Ni}_{2} \mathrm{P} @ \mathrm{Ni}-\mathrm{MOF} / \mathrm{NF}$ electrode was evaluated by using LSV technique in $1 \mathrm{M} \mathrm{NaOH}$ containing $0.33 \mathrm{M}$ urea. From Fig. 7a, $\mathrm{Ni}_{2} \mathrm{P} @ \mathrm{Ni}-\mathrm{MOF} / \mathrm{NF}$ electrode had apparent better electrocatalytic activity for HER compared with other electrodes. The overpotential at current density of $10 \mathrm{~mA} \mathrm{~cm}-2\left(\eta_{10}\right)$ follows the order: $\mathrm{Ni}_{2} \mathrm{P} @ \mathrm{NiC} / \mathrm{NF}(57 \mathrm{mV})<\mathrm{Ni}_{2} \mathrm{P} @ \mathrm{Ni}-\mathrm{MOF} / \mathrm{NF}(6 \mathrm{mV})<\mathrm{NiC} / \mathrm{NF}$ $(78 \mathrm{mV})<$ pNF $(144 \mathrm{mV})<\mathrm{Ni}-\mathrm{MOF} / \mathrm{NF}(165 \mathrm{mV})<\mathrm{NF}(200 \mathrm{mV})$. The result clearly manifested that phosphidation and carbonization could dramatically boost the HER performance of the Ni-MOF. Although the $\eta_{10}$ of $\mathrm{Ni}_{2} \mathrm{P} @ \mathrm{Ni}-\mathrm{MOF} / \mathrm{NF}$ was larger than that of $\mathrm{Ni}_{2} \mathrm{P} @ \mathrm{NiC} / \mathrm{NF}$, the performance of electrode at large current density was inferior to the latter one. Moreover, the mechanical properties of $\mathrm{Ni}_{2} \mathrm{P} @ \mathrm{NiC} / \mathrm{NF}$ were very poor, material fragments kept falling off the electrode during the electrochemical test. The HER activity of the $\mathrm{Ni}_{2} \mathrm{P} @ \mathrm{Ni}-\mathrm{MOF} /$ NF electrode, in terms of the $\eta_{10}$ value, is lower than many state-of-the-art NF based HER electrodes such as $\mathrm{NiFe}-\mathrm{MOF} / \mathrm{NF}(134 \mathrm{mV})$ and $\mathrm{Ni}_{2} \mathrm{P} / \mathrm{Ni} / \mathrm{NF}(98 \mathrm{mV})$ (Table S3) ${ }^{18,55-60}$. The Tafel slope of $\mathrm{Ni}_{2} \mathrm{P} @ \mathrm{Ni}-\mathrm{MOF} / \mathrm{NF}$ was

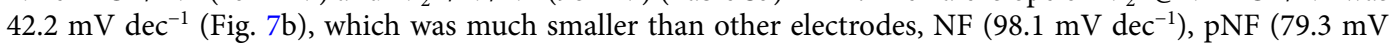
$\left.\mathrm{dec}^{-1}\right), \mathrm{Ni}-\mathrm{MOF} / \mathrm{NF}\left(76.6 \mathrm{mV} \mathrm{dec}{ }^{-1}\right) \mathrm{NiC} / \mathrm{NF}\left(39.3 \mathrm{mV} \mathrm{dec}^{-1}\right)$ and $\mathrm{Ni}_{2} \mathrm{P} @ \mathrm{NiC} / \mathrm{NF}\left(31.3 \mathrm{mV} \mathrm{dec}^{-1}\right)$. The results indicated that the $\mathrm{Ni}_{2} \mathrm{P} @ \mathrm{Ni}-\mathrm{MOF} / \mathrm{NF}$ electrode had faster HER kinetics than other electrodes. Since the Tafel

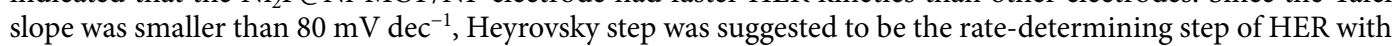
$\mathrm{Ni}_{2} \mathrm{P} @ \mathrm{Ni}-\mathrm{MOF} / \mathrm{NF}$ electrode ${ }^{61}$.

The Nyquist plots of various electrodes for HER are presented in Fig. 7c. The fitting parameters of impedance spectra of HER are summarized in Table S4. It can be clearly seen that the charge transfer resistance of the electrodes follows the same order as that for UOR. The results evidently confirmed that direct phosphidation process could significantly boost the conductivity of $\mathrm{Ni}-\mathrm{MOF}$. The electrochemical stability of $\mathrm{Ni}_{2} \mathrm{P} @ \mathrm{Ni}-\mathrm{MOF} / \mathrm{NF}$ electrode for HER was further tested by chronoamperometry at $-0.1 \mathrm{~V}$ (vs RHE) for $10 \mathrm{~h}$. As shown in Fig. 7d, the current density gradually increased from -25 to $-20 \mathrm{~mA} \mathrm{~cm}^{-2}$ in the first hour, which may be attributed to the slowly buildup of hydrogen gases bubbles on the surface of the electrode. At the end of the stability test, the current density still remained about $79.3 \%$ of the initial value. No obvious deterioration was observed for the LSV curves before and after stability test (Fig. 7e), substantiated the excellent durability of the electrode $\mathrm{e}^{62-65}$. 

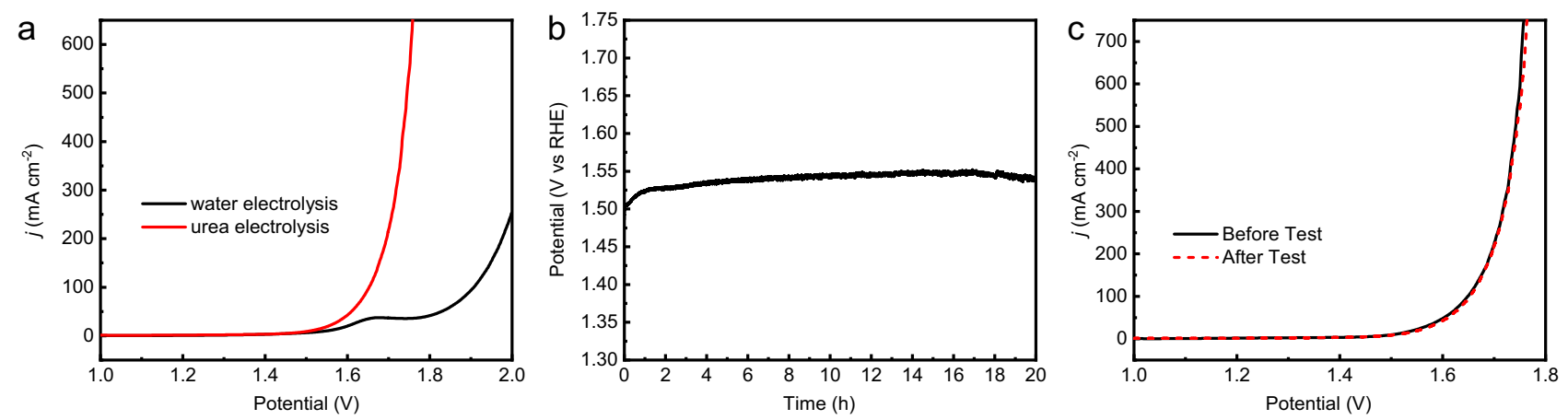

Figure 8. (a) LSV polarization curve of urea electrolyzed by $\mathrm{Ni}_{2} \mathrm{P} @ \mathrm{Ni}-\mathrm{MOF} / \mathrm{NF}$ electrode in $1 \mathrm{M} \mathrm{NaOH}$ with or without $0.33 \mathrm{M}$ urea. (b) Chronopotentiometric (V-t) curve of $\mathrm{Ni}_{2} \mathrm{P} @ \mathrm{Ni}-\mathrm{MOF} / \mathrm{NF} / / \mathrm{Ni} \mathrm{P}_{2} \mathrm{P} @ \mathrm{Ni}-\mathrm{MOF} / \mathrm{NF}$ for urea comprehensive electrolysis at current density of $10 \mathrm{~mA} \mathrm{~cm}^{-2}$. (c) LSV curve of $\mathrm{Ni}_{2} \mathrm{P} @ \mathrm{Ni}-\mathrm{MOF} / \mathrm{NF}$ before and after $20 \mathrm{~h}$ UOR test.

Urea electrolysis. Given the fact that $\mathrm{Ni}_{2} \mathrm{P} @ \mathrm{Ni}-\mathrm{MOF} / \mathrm{NF}$ electrode has excellent performance for both UOR and HER, we constructed an electrolyzer with $\mathrm{Ni}_{2} \mathrm{P} @ \mathrm{Ni}-\mathrm{MOF} / \mathrm{NF}$ as bifunctional electrode for urea assisted hydrogen production. As shown in Fig. 8a, the electrolyzer could deliver a current density of $100 \mathrm{~mA} \mathrm{~cm}{ }^{-2}$ at $1.65 \mathrm{~V}$ for urea electrolysis. While a much higher potential of $1.91 \mathrm{~V}$ was required to drive water electrolysis at the same current density. The result clearly demonstrated the advantage of urea electrolysis over water electrolysis for hydrogen production. Compared with other reported electrodes, the $\mathrm{Ni}_{2} \mathrm{P} @ \mathrm{Ni}-\mathrm{MOF} / \mathrm{NF}$ was among the best ones for urea electrolysis (Table S3).

The long-term stability for urea electrolysis with $\mathrm{Ni}_{2} \mathrm{P} @ \mathrm{Ni}-\mathrm{MOF} / \mathrm{NF}$ electrode at a current density of $10 \mathrm{~mA} \mathrm{~cm}^{-2}$ by chronopotentiometry (V-t). In Fig. 8b, the voltage increase in the first hour was attributed to the buildup of hydrogen gas bubbles on the surface of the cathode, consistent with that observed in Fig. 7d. At the end of the 20 -h longevity test, the applied potential increased by only $1.1 \%$, demonstrating the excellent longevity of the sample as bifunctional electrode for urea electrolysis. No appreciable change can be observed for the LSV curves obtained in 2-electrode configuration before and after stability test (Fig. 8c), advocating the excellent stability of the electrode. The results showed that $\mathrm{Ni}_{2} \mathrm{P} @ \mathrm{Ni}-\mathrm{MOF} / \mathrm{NF}$ was a promising bifunctional electrode for urea electrolysis.

\section{Conclusions}

In summary, $\mathrm{Ni}_{2} \mathrm{P} @ \mathrm{Ni}-\mathrm{MOF}$ nanosheets were successfully grown on nickel foam through direct phosphidation of Ni-MOF nanosheets. The Ni-MOF structure was partially preserved as confirmed by XRD, TGA and FTIR characterization. The self-supporting $\mathrm{Ni}_{2} \mathrm{P} @ \mathrm{Ni}-\mathrm{MOF} / \mathrm{NF}$ exhibited excellent electrochemical performance for both UOR and HER. It only required $1.41 \mathrm{~V}$ and $66 \mathrm{mV}$ (vs RHE) to deliver a current density of $100 \mathrm{~mA} \mathrm{~cm}^{-2}$ for UOR and $10 \mathrm{~mA} \mathrm{~cm}^{-2}$ for HER, respectively. The excellent UOR and HER performances of the $\mathrm{Ni}_{2} \mathrm{P} @ \mathrm{Ni}-\mathrm{MOF} /$ NF were attributed to both the enhanced conductivity and the fast release of the gases bubbles from the surfaces of the electrode. The electrolyzer constructed with $\mathrm{Ni}_{2} \mathrm{P} @ \mathrm{Ni}-\mathrm{MOF} / \mathrm{NF}$ as both anode and cathode could deliver a current density of $100 \mathrm{~mA} \mathrm{~cm}^{-2}$ in $1 \mathrm{M} \mathrm{NaOH}$ with the presence of $0.33 \mathrm{M}$ urea at $1.65 \mathrm{~V}$, which was $0.26 \mathrm{~V}$ lower than water electrolysis. Furthermore, the $\mathrm{Ni}_{2} \mathrm{P} @ \mathrm{Ni}-\mathrm{MOF} / \mathrm{NF}$ also demonstrated excellent longevity for urea electrolysis. Considering the low cost, easy preparation, long term stability and excel activity, $\mathrm{Ni}_{2} \mathrm{P} @ \mathrm{Ni}-\mathrm{MOF} / \mathrm{NF}$ electrode could be a promising bifunctional electrode for hydrogen production through urea electrolysis and to retrieve energy from urea-rich wastewater.

\section{Methods}

Chemicals and materials. Nickel chloride hexahydrate $\left(\mathrm{NiCl}_{2} \cdot 6 \mathrm{H}_{2} \mathrm{O}\right), \mathrm{N}, \mathrm{N}$-dimethylmethanamide $\left(\mathrm{C}_{4} \mathrm{H}_{9} \mathrm{NO}, \mathrm{DMF}\right)$, 1,4-benzenedicarboxylic acid $\left(\mathrm{C}_{7} \mathrm{H}_{6} \mathrm{O}_{2}, \mathrm{BDC}\right)$, ethanol $\left(\mathrm{C}_{2} \mathrm{H}_{6} \mathrm{O}\right)$, acetone $\left(\mathrm{C}_{3} \mathrm{H}_{6} \mathrm{O}\right)$, urea $\left(\mathrm{CH}_{4} \mathrm{~N}_{2} \mathrm{O}\right)$, sodium hydroxide $(\mathrm{NaOH})$ and sodium hypophosphite $\left(\mathrm{NaH}_{2} \mathrm{PO}_{2}\right)$ were bought from Aladdin (Shanghai, China). Nickel foam (NF) was purchased from Shenzhen Green Creative Environment Technology Co. Ltd. (Shenzhen, China). All of the chemicals and materials were used as received without further purification. Ultrapure water generated using a Ulupure system was used throughout all experiments.

Synthesis of Ni-MOF/NF. Typically, $0.188 \mathrm{mmol} \mathrm{NiCl}_{2} \cdot 6 \mathrm{H}_{2} \mathrm{O}$ and $0.375 \mathrm{mmol} \mathrm{BDC}$ were dissolved in a mixture solvent containing $16 \mathrm{~mL}$ DMF, $1 \mathrm{~mL}$ ethanol and $1 \mathrm{~mL}$ water to form a clear solution. The NF was cut into small pieces $(2 \mathrm{~cm} \times 3 \mathrm{~cm})$ and sonicated in $2 \mathrm{M} \mathrm{HCl}$ for $15 \mathrm{~min}$ to remove surface oxides. After washed with copious water and blown dry with pure nitrogen gas, it was then transferred into a Teflon-lined hydrothermal reactor with the above-mentioned solution. Subsequently, the hydrothermal reactor was heated in an oven at $140{ }^{\circ} \mathrm{C}$ for $48 \mathrm{~h}$ to grow Ni-MOF on NF. Finally, the sample was rinsed with ethanol and ultrapure water thoroughly and dried in air for later use.

Synthesis of $\mathrm{Ni}_{2} \mathrm{P} @ \mathrm{Ni}-\mathrm{MOF} / \mathrm{NF}$. To synthesis $\mathrm{Ni}_{2} \mathrm{P} @ \mathrm{Ni}-\mathrm{MOF} / \mathrm{NF}$, the Ni-MOF/NF and $\mathrm{NaH}_{2} \mathrm{PO}_{2}$ with a mass ratio of 1:4 were placed on both sides of a porcelain boat. The porcelain boat was then put in a quartz 
tubing that housed in a tube furnace. The $\mathrm{NaH}_{2} \mathrm{PO}_{2}$ was placed on the upstream of the gas flow. Afterwards, the phosphidation process was carried out for two hours at $300{ }^{\circ} \mathrm{C}$ under $\mathrm{Ar}$ flow. The sample was labelled as $\mathrm{Ni}_{2} \mathrm{P} @$ $\mathrm{Ni}-\mathrm{MOF} / \mathrm{NF}$. For comparison, the Ni-MOF was fist calcined at $600{ }^{\circ} \mathrm{C}$ for $2 \mathrm{~h}$ under the protection of Ar to get $\mathrm{NiC} / \mathrm{NF}$, which was subsequently phosphidized using the same procedure to obtain $\mathrm{Ni}_{2} \mathrm{P} @ \mathrm{NiC} / \mathrm{NF}$. Direct phosphidation of NF was also performed using the same procedure and the electrode was labelled as pNF.

Characterization. The morphology of the material was characterized by using scanning electron microscopy (SEM, TESCAN MIRA 3, Czech) equipped with an energy-dispersive X-ray spectrometer (EDX) and transmission electron microscope (HR-TEM, JEM-2010, Japan). X-ray diffraction patterns (XRD, Ulitma IV, Japan) were obtained on a PANalytical XPert instrument with $\mathrm{Cu}$ Ka radiation $(\lambda=0.1542 \mathrm{~nm})$. X-ray photoelectron spectroscopy (XPS, Thermo ESCALAB 250XI, America) was used to study the composition and chemical state of the samples using an $\mathrm{Al} \mathrm{Ka} \mathrm{X-ray} \mathrm{source,} \mathrm{and} \mathrm{the} \mathrm{binding} \mathrm{energy} \mathrm{was} \mathrm{calibrated} \mathrm{according} \mathrm{to} \mathrm{the} \mathrm{refer-}$ ence $\mathrm{C} 1 \mathrm{~s}$ peak at $284.6 \mathrm{eV}$.

Electrochemical measurements. Except the test with the electrolyzer, all electrochemical measurements were performed in standard three-electrode configuration on a $\mathrm{CHI} 760 \mathrm{E}$ potentiostat with $\mathrm{Ag} / \mathrm{AgCl}$ and graphite rod used as reference and counter electrode, respectively. The potentials were reported against reversible hydrogen electrode (RHE) scale by converting the measured potential using the following equation,

$$
E_{\mathrm{RHE}}=E_{\mathrm{Ag} / \mathrm{AgCl}}+0.059 \times \mathrm{pH}+E_{\mathrm{Ag} / \mathrm{AgCl}}^{\circ}
$$

Electrochemical impedance spectra (EIS) were recorded in the frequency range of $100 \mathrm{kHz}$ to $0.1 \mathrm{~Hz}$ at a voltage amplitude of $5 \mathrm{mV}$. The EIS spectra were fitted to obtain the charge transfer resistance, $\mathrm{R}_{\mathrm{ct}}$. The electrochemical double-layer capacitance $\left(\mathrm{C}_{\mathrm{dl}}\right)$ of electrodes were evaluated by using cyclic voltammetry at scan rates of $20,40,60,80,100$ and $120 \mathrm{mV} \mathrm{s}^{-1}$ in a non-Faradic potential range.

Received: 23 August 2021; Accepted: 5 October 2021

Published online: 01 November 2021

\section{References}

1. Zhou, J. et al. Layered metal-organic framework-derived metal oxide/carbon nanosheet arrays for catalyzing the oxygen evolution reaction. ACS Energy Lett. 3, 1655-1661. https://doi.org/10.1021/acsenergylett.8b00809 (2018).

2. Cai, G., Zhang, W., Jiao, L., Yu, S.-H. \& Jiang, H.-L. Template-directed growth of well-aligned MOF arrays and derived selfsupporting electrodes for water splitting. Chem 2, 791-802. https://doi.org/10.1016/j.chempr.2017.04.016 (2017).

3. Liang, Z., Zhao, R., Qiu, T., Zou, R. \& Xu, Q. Metal-organic framework-derived materials for electrochemical energy applications. EnergyChem 1, 100001. https://doi.org/10.1016/j.enchem.2019.100001 (2019).

4. Indra, A., Song, T. \& Paik, U. Metal organic framework derived materials: progress and prospects for the energy conversion and storage. Adv. Mater. 30, 1705146. https://doi.org/10.1002/adma.201705146 (2018).

5. $\mathrm{Qu}, \mathrm{H}$. et al. $\mathrm{Ni}_{2} \mathrm{P} / \mathrm{C}$ nanosheets derived from oriented growth Ni-MOF on nickel foam for enhanced electrocatalytic hydrogen evolution. J. Colloid Interface Sci. 572, 83-90. https://doi.org/10.1016/j.jcis.2020.03.068 (2020).

6. Wang, X. et al. Chemical and morphological transformation of MOF-derived bimetallic phosphide for efficient oxygen evolution. Nano Energy 62, 745-753. https://doi.org/10.1016/j.nanoen.2019.06.002 (2019).

7. Xu, Y. et al. Ir-Doped Ni-based metal-organic framework ultrathin nanosheets on Ni foam for enhanced urea electro-oxidation. Chem. Commun. 56, 2151-2154. https://doi.org/10.1039/C9CC09484A (2020).

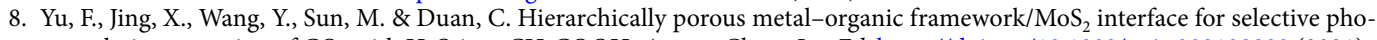
tocatalytic conversion of $\mathrm{CO}_{2}$ with $\mathrm{H}_{2} \mathrm{O}$ into $\mathrm{CH}_{3} \mathrm{COOH}$. Angew. Chem. Int. Ed. https://doi.org/10.1002/anie.202108892 (2021).

9. Tahir, M. et al. Electrocatalytic oxygen evolution reaction for energy conversion and storage: a comprehensive review. Nano Energy 37, 136-157. https://doi.org/10.1016/j.nanoen.2017.05.022 (2017).

10. Schalenbach, M. et al. Gas permeation through nafion. Part 1: measurements. J. Phys. Chem. C 119, 25145-25155. https://doi.org/ 10.1021/acs.jpcc.5b04155 (2015).

11. You, B. \& Sun, Y. Innovative strategies for electrocatalytic water splitting. Acc. Chem. Res. 51, 1571-1580. https://doi.org/10.1021/ acs.accounts.8b00002 (2018).

12. Xu, X. et al. A perovskite electrocatalyst for efficient hydrogen evolution reaction. Adv. Mater. 28, 6442-6448. https://doi.org/10. 1002/adma.201600005 (2016).

13. Zhong, W. et al. The pulsed laser-induced Schottky junction via in-situ forming Cd clusters on CdS surfaces toward efficient visible light-driven photocatalytic hydrogen evolution. Appl. Catal. B Environ. 258, 117967. https://doi.org/10.1016/j.apcatb.2019.117967 (2019).

14. Largeron, M. Protocols for the catalytic oxidation of primary amines to imines. Eur. J. Org. Chem. 2013, 5225-5235. https://doi. org/10.1002/ejoc.201300315 (2013).

15. Lhermitte, C. R. \& Sivula, K. Alternative oxidation reactions for solar-driven fuel production. ACS Catal. 9, 2007-2017. https:// doi.org/10.1021/acscatal.8b04565 (2019).

16. Chen, Y. X. et al. Nanotechnology makes biomass electrolysis more energy efficient than water electrolysis. Nat. Commun. 5, 4036. https://doi.org/10.1038/ncomms5036 (2014).

17. Zhang, L. et al. A lattice-oxygen-involved reaction pathway to boost urea oxidation. Angew. Chem. Int. Ed. 58, 16820-16825. https://doi.org/10.1002/anie.201909832 (2019).

18. Xu, Y. et al. Metal-organic frameworks-derived Ru-doped Co2P/N-doped carbon composite nanosheet arrays as bifunctional electrocatalysts for hydrogen evolution and urea oxidation. Chem. Eng. J. 408, 127308. https://doi.org/10.1016/j.cej.2020.127308 (2021).

19. Tong, Y. et al. Oxygen vacancies confined in nickel molybdenum oxide porous nanosheets for promoted electrocatalytic urea oxidation. ACS Catal. 8, 1-7. https://doi.org/10.1021/acscatal.7b03177 (2018).

20. Boggs, B. K., King, R. L. \& Botte, G. G. Urea electrolysis: direct hydrogen production from urine. Chem. Commun. https://doi.org/ 10.1039/B905974A (2009).

21. Vedharathinam, V. \& Botte, G. G. Understanding the electro-catalytic oxidation mechanism of urea on nickel electrodes in alkaline medium. Electrochim. Acta 81, 292-300. https://doi.org/10.1016/j.electacta.2012.07.007 (2012). 
22. Zhu, X. et al. Metallic nickel hydroxide nanosheets give superior electrocatalytic oxidation of urea for fuel cells. Angew. Chem. Int. Ed. 55, 12465-12469. https://doi.org/10.1002/anie.201606313 (2016).

23. Liu, M., Jiao, Y., Zhan, S. \& Wang, H. Ni3S2 nanowires supported on Ni foam as efficient bifunctional electrocatalyst for ureaassisted electrolytic hydrogen production. Catal. Today 355, 596-601. https://doi.org/10.1016/j.cattod.2019.05.032 (2020).

24. Mirzaei, P. et al. Electrochemical oxidation of urea on nickel-rhodium nanoparticles/carbon composites. Electrochim. Acta 297, 715-724. https://doi.org/10.1016/j.electacta.2018.11.205 (2019).

25. King, R. L. \& Botte, G. G. Investigation of multi-metal catalysts for stable hydrogen production via urea electrolysis. J. Power Sour. 196, 9579-9584. https://doi.org/10.1016/j.jpowsour.2011.06.079 (2011).

26. Zeng, M. et al. Interlayer effect in NiCo layered double hydroxide for promoted electrocatalytic urea oxidation. ACS Sustain. Chem. Eng. 7, 4777-4783. https://doi.org/10.1021/acssuschemeng.8b04953 (2019).

27. Wang, D., Yan, W., Vijapur, S. H. \& Botte, G. G. Enhanced electrocatalytic oxidation of urea based on nickel hydroxide nanoribbons. J. Power Sourc. 217, 498-502. https://doi.org/10.1016/j.jpowsour.2012.06.029 (2012).

28. Yan, W., Wang, D. \& Botte, G. G. Electrochemical decomposition of urea with Ni-based catalysts. Appl. Catal. B Environ. 127, 221-226. https://doi.org/10.1016/j.apcatb.2012.08.022 (2012).

29. Adhikari, S., Kwon, Y. \& Kim, D. H. Three-dimensional core-shell structured $\mathrm{NiCo}_{2} \mathrm{O}_{4} @ \mathrm{CoS} / \mathrm{Ni}$-foam electrocatalyst for oxygen evolution reaction and electrocatalytic oxidation of urea. Chem. Eng. J. https://doi.org/10.1016/j.cej.2020.126192 (2020).

30. Liu, Z., Zhang, C., Liu, H. \& Feng, L. Efficient synergism of $\mathrm{NiSe}_{2}$ nanoparticle/NiO nanosheet for energy-relevant water and urea electrocatalysis. Appl. Catal. B Environ. 276, 119165. https://doi.org/10.1016/j.apcatb.2020.119165 (2020).

31. Sha, L. et al. In situ grown 3D hierarchical $\mathrm{MnCo}_{2} \mathrm{O}_{4.5} @ \mathrm{Ni}(\mathrm{OH})_{2}$ nanosheet arrays on $\mathrm{Ni}$ foam for efficient electrocatalytic urea oxidation. Chem. Eng. J. https://doi.org/10.1016/j.cej.2019.122603 (2020).

32. Wang, D., Vijapur, S. H., Wang, Y. \& Botte, G. G. $\mathrm{NiCo}_{2} \mathrm{O}_{4}$ nanosheets grown on current collectors as binder-free electrodes for hydrogen production via urea electrolysis. Int. J. Hydrog. Energy 42, 3987-3993. https://doi.org/10.1016/j.ijhydene.2016.11.048 (2017).

33. Wang, X. et al. Hierarchical coral-like NiMoS nanohybrids as highly efficient bifunctional electrocatalysts for overall urea electrolysis. Nano Res. 11, 988-996. https://doi.org/10.1007/s12274-017-1711-3 (2018).

34. Liu, H. et al. $\mathrm{Ni}_{2} \mathrm{P}$ nanoflakes for the high-performing urea oxidation reaction: linking active sites to a UOR mechanism. Nanoscale 13, 1759-1769. https://doi.org/10.1039/D0NR08025J (2021).

35. Tang, C. et al. Energy-saving electrolytic hydrogen generation: $\mathrm{Ni}_{2} \mathrm{P}$ nanoarray as a high-performance non-noble-metal electrocatalyst. Angew. Chem. Int. Ed. 56, 842-846. https://doi.org/10.1002/anie.201608899 (2017).

36. Rostamnia, S. \& Karimi, Z. Preparation and catalytically study of metal-organic frameworks of amine/MIL-53 (Al) as a powerful option in the rapid N-formylation condensation in neat conditions. Inorg. Chim. Acta 428, 133-137. https://doi.org/10.1016/j.ica. 2015.01.031 (2015).

37. Mantasha, I. et al. Efficient and selective adsorption and separation of methylene blue (MB) from mixture of dyes in aqueous environment employing a $\mathrm{Cu}(\mathrm{II})$ based metal organic framework. Inorg. Chim. Acta 511, 119787. https://doi.org/10.1016/j.ica. 2020.119787 (2020).

38. Ma, H., Wang, H., Wu, T. \& Na, C. Highly active layered double hydroxide-derived cobalt nano-catalysts for p-nitrophenol reduction. Appl. Catal. B Environ. 180, 471-479. https://doi.org/10.1016/j.apcatb.2015.06.052 (2016).

39. Zhu, D. et al. Two-dimensional metal-organic frameworks with high oxidation states for efficient electrocatalytic urea oxidation. Chem. Commun. 53, 10906-10909. https://doi.org/10.1039/C7CC06378D (2017).

40. Duan, J., Chen, S. \& Zhao, C. Ultrathin metal-organic framework array for efficient electrocatalytic water splitting. Nat. Commun. https://doi.org/10.1038/ncomms15341 (2017).

41. Wang, M. et al. Metal-organic framework derived carbon-confined $\mathrm{Ni}_{2} \mathrm{P}$ nanocrystals supported on graphene for an efficient oxygen evolution reaction. Chem. Commun. 53, 8372-8375. https://doi.org/10.1039/C7CC03558F (2017).

42. Huang, Z. et al. Cobalt phosphide nanorods as an efficient electrocatalyst for the hydrogen evolution reaction. Nano Energy 9 , 373-382. https://doi.org/10.1016/j.nanoen.2014.08.013 (2014).

43. Liang, J., Wang, Y.-Z., Wang, C.-C. \& Lu, S.-Y. In situ formation of $\mathrm{NiO}$ on $\mathrm{Ni}$ foam prepared with a novel leaven dough method as an outstanding electrocatalyst for oxygen evolution reactions. J. Mater. Chem. A 4, 9797-9806. https://doi.org/10.1039/C6TA0 3729A (2016).

44. Pu, Z., Liu, Q., Tang, C., Asiri, A. M. \& Sun, X. Ni2P nanoparticle films supported on a Ti plate as an efficient hydrogen evolution cathode. Nanoscale 6, 11031-11034. https://doi.org/10.1039/c4nr03037k (2014).

45. Zhan, S., Zhou, Z., Liu, M., Jiao, Y. \& Wang, H. 3D NiO nanowalls grown on Ni foam for highly efficient electro-oxidation of urea. Catal. Today 327, 398-404. https://doi.org/10.1016/j.cattod.2018.02.049 (2019).

46. Zheng, W., Liu, M. \& Lee, L. Y. S. Best practices in using foam-type electrodes for electrocatalytic performance benchmark. ACS Energy Lett. 5, 3260-3264. https://doi.org/10.1021/acsenergylett.0c01958 (2020).

47. Moysiadou, A., Lee, S., Hsu, C.-S., Chen, H. M. \& Hu, X. Mechanism of oxygen evolution catalyzed by cobalt oxyhydroxide: cobalt superoxide species as a key intermediate and dioxygen release as a rate-determining step. J. Am. Chem. Soc. 142, 11901-11914. https://doi.org/10.1021/jacs.0c04867 (2020).

48. Tkalych, A. J., Zhuang, H. L. \& Carter, E. A. A density functional+ U assessment of oxygen evolution reaction mechanisms on B-NiOOH. ACS Catal. 7, 5329-5339 (2017).

49. Zhao, X., Ren, H. \& Luo, L. Gas bubbles in electrochemical gas evolution reactions. Langmuir 35, 5392-5408. https://doi.org/10. 1021/acs.langmuir.9b00119 (2019).

50. Xie, J. et al. Defect-rich $\mathrm{MoS}_{2}$ ultrathin nanosheets with additional active edge sites for enhanced electrocatalytic hydrogen evolution. Adv. Mater. 25, 5807-5813. https://doi.org/10.1002/adma.201302685 (2013).

51. Dastafkan, K., Li, Y., Zeng, Y., Han, L. \& Zhao, C. Enhanced surface wettability and innate activity of an iron borate catalyst for efficient oxygen evolution and gas bubble detachment. J. Mater. Chem. A 7, 15252-15261. https://doi.org/10.1039/C9TA03346G (2019).

52. Zhao, T. et al. Vertical growth of porous perovskite nanoarrays on nickel foam for efficient oxygen evolution reaction. ACS Sustain. Chem. Eng. 8, 4863-4870. https://doi.org/10.1021/acssuschemeng.0c00060 (2020).

53. Mabayoje, O. et al. Hydrogen evolution by $\mathrm{Ni}_{2} \mathrm{P}$ catalysts derived from phosphine MOFs. ACS Appl. Energy Mater. 3, 176-183. https://doi.org/10.1021/acsaem.9b02109 (2020).

54. Das, M. et al. Single-phase $\mathrm{Ni}_{5} \mathrm{P}_{4}$-copper foam superhydrophilic and aerophobic core-shell nanostructures for efficient hydrogen evolution reaction. J. Mater. Chem. A 7, 23989-23999. https://doi.org/10.1039/C9TA06729A (2019).

55. Xu, Y. et al. Nickel nanoparticles encapsulated in few-layer nitrogen-doped graphene derived from metal-organic frameworks as efficient bifunctional electrocatalysts for overall water splitting. Adv. Mater. 29, 1605957. https://doi.org/10.1002/adma.20160 5957 (2017).

56. $\mathrm{Xu}$, Y. et al. Low-ruthenium-content $\mathrm{NiRu}$ nanoalloys encapsulated in nitrogen-doped carbon as highly efficient and $\mathrm{pH}$-universal electrocatalysts for the hydrogen evolution reaction. J. Mater. Chem. A 6, 1376-1381. https://doi.org/10.1039/C7TA09939H (2018).

57. Duan, J., Chen, S., Vasileff, A. \& Qiao, S. Z. Anion and cation modulation in metal compounds for bifunctional overall water splitting. ACS Nano 10, 8738-8745. https://doi.org/10.1021/acsnano.6b04252 (2016). 
58. You, B., Jiang, N., Sheng, M., Bhushan, M. W. \& Sun, Y. Hierarchically porous urchin-like $\mathrm{Ni}_{2} \mathrm{P}$ superstructures supported on nickel foam as efficient bifunctional electrocatalysts for overall water splitting. ACS Catal. 6, 714-721. https://doi.org/10.1021/acscatal. 5 b02193 (2016).

59. Chen, P. et al. 3D nitrogen-anion-decorated nickel sulfides for highly efficient overall water splitting. Adv. Mater. 29, 1701584. https://doi.org/10.1002/adma.201701584 (2017).

60. Xiao, C., $\mathrm{Li}, \mathrm{Y}$., $\mathrm{Lu}, \mathrm{X}$. \& Zhao, C. Bifunctional porous $\mathrm{NiFe} / \mathrm{NiCo}_{2} \mathrm{O}_{4} / \mathrm{Ni}$ foam electrodes with triple hierarchy and double synergies for efficient whole cell water splitting. Adv. Funct. Mater. 26, 3515-3523. https://doi.org/10.1002/adfm.201505302 (2016).

61. Shinagawa, T., Garcia-Esparza, A. T. \& Takanabe, K. Insight on Tafel slopes from a microkinetic analysis of aqueous electrocatalysis for energy conversion. Sci. Rep. 5, 13801. https://doi.org/10.1038/srep13801 (2015).

62. Zhang, G. et al. Enhanced catalysis of electrochemical overall water splitting in alkaline media by $\mathrm{Fe}$ doping in $\mathrm{Ni}_{3} \mathrm{~S}_{2}$ nanosheet arrays. ACS Catal. 8, 5431-5441. https://doi.org/10.1021/acscatal.8b00413 (2018).

63. Cheng, J. et al. Editable asymmetric all-solid-state supercapacitors based on high-strength, flexible, and programmable 2D-metalorganic framework/reduced graphene oxide self-assembled papers. J. Mater. Chem. A 6, 20254-20266. https://doi.org/10.1039/ c8ta06785f (2018).

64. Ge, Y. et al. Transforming nickel hydroxide into $3 \mathrm{D}$ prussian blue analogue array to obtain $\mathrm{Ni}_{2} \mathrm{P} / \mathrm{Fe}_{2} \mathrm{P}$ for efficient hydrogen evolution reaction. Adv. Energy Mater. 8, 1800484. https://doi.org/10.1002/aenm.201800484 (2018).

65. Jiang, P. et al. A cost-effective 3D hydrogen evolution cathode with high catalytic activity: FeP nanowire array as the active phase. Angew. Chem. Int. Ed. 53, 12855-12859. https://doi.org/10.1002/anie.201406848 (2014).

\section{Acknowledgements}

The authors acknowledge the financial support by National Natural Science Foundation of China (No. 22036004), National Key R\&D Program of China (2018YFC1802002), NCC fund (No. NCC2020PY16), the Tianjin Commission of Science and Technology as key technologies R\&D projects (No. 18YFZCSF00770, 18ZXSZSF00230, 18YFZCSF00500), the Fundamental Research Funds for the Central Universities Nankai University (No. $63191408,51208267)$.

\section{Author contributions}

Conceptualization, H.W. and T.L.; Methodology, H.W. and H.Z.; Investigation, H.Z., Y.L., Z.L., W.S. and S.L.; Writing-Original draft, H.Z. and H.W.; Writing-Review \& Editing, H.W., S.L. and K.L.; Visualization, H.Z. and H.W.; Supervision, H.W. and T.L.; Funding Acquisition, H.W. and T.L. All authors reviewed the manuscript.

\section{Competing interests}

The authors declare no competing interests.

\section{Additional information}

Supplementary Information The online version contains supplementary material available at https://doi.org/ 10.1038/s41598-021-00776-8.

Correspondence and requests for materials should be addressed to T.L. or S.L.

Reprints and permissions information is available at www.nature.com/reprints.

Publisher's note Springer Nature remains neutral with regard to jurisdictional claims in published maps and institutional affiliations.

(c) (i) Open Access This article is licensed under a Creative Commons Attribution 4.0 International License, which permits use, sharing, adaptation, distribution and reproduction in any medium or format, as long as you give appropriate credit to the original author(s) and the source, provide a link to the Creative Commons licence, and indicate if changes were made. The images or other third party material in this article are included in the article's Creative Commons licence, unless indicated otherwise in a credit line to the material. If material is not included in the article's Creative Commons licence and your intended use is not permitted by statutory regulation or exceeds the permitted use, you will need to obtain permission directly from the copyright holder. To view a copy of this licence, visit http://creativecommons.org/licenses/by/4.0/.

(C) The Author(s) 2021 